\title{
In vitro Crude Fibre Disappearance of Brewery Waste Incorporated Paddy Straw in Rusitec
}

\author{
S. Senthilkumar ${ }^{*}$ \\ Department of Animal Nutrition, College of Veterinary and Animal Sciences (COVAS), \\ Mannuthy - 680 651, Thrissur, Kerala, India \\ *Corresponding author
}

\begin{abstract}
A B S T R A C T
Keywords

Brewery waste, Paddy straw, Crude fibre disappearance, In vitro, RUSITEC

Article Info

Accepted:

20 July 2020

Available Online:

10 August 2020

An in vitro experiment was conducted to study the in vitro crude fibre disappearance of the following seven experimental feeds such as 1) Control feed; 2) Experimental feed $(75 \%)+$ Fresh brewery waste $(25 \%)$ (EFFBW); 3) Experimental feed $(75 \%)+$ Dried brewery waste (25\%) (EFDBW); 4) Fresh brewery waste (FBW); 5) Dried brewery waste (DBW); 6) Paddy straw (PS) and 7) Brewery waste incorporated paddy straw (BWIPS) incubated for 2, 6, 12, 24, 48 and 72 hours in Rumen Simulation Technique (RUSITEC). During initial incubation periods (2, 6, 12 and 24 hours), the control feed, EFFBW, EFDBW and FBW showed higher in vitro crude fibre disappearance than other experimental feeds, whereas, during later incubation periods (48 and 72 hours), the DBW, paddy straw and BWIPS showed higher in vitro crude fibre disappearance than other experimental feeds incubated in RUSITEC.
\end{abstract}

\section{Introduction}

Brewery waste is a by product of ethanol industry which uses cereal grains as feed stock. Distiller's grain has a moderate content of protein and high level of crude fibre which make it an attractive ingredient to be used in ruminant feed (Rasco et al., 1989). Among the various cereal crop residues, paddy straw (Oryza sativa) is the main roughage source for majority of cattle and buffaloes reared in Indian small holdings. However, the nutrient digestibility of straw is very poor. Knowledge on disappearance / degradability of brewery waste incorporated with paddy straw would throw more light on its usefulness and would help to formulate complete feed for dairy cattle. The present study was undertaken to evaluate the in vitro crude fibre disappearance of brewery waste incorporated paddy straw based feeds using Rumen Simulation Technique (RUSITEC).

\section{Materials and Methods}

Per cent ingredient composition of the control and experimental concentrate mixtures used are presented in Table 1. The Dry matter (DM) composition of Control feed, Experimental feed, Brewery waste, Paddy 
straw and Brewery waste incorporated paddy straw were carried out as per standard procedure (AOAC, 1990) and was $95.15 \pm$ $0.56,94.76 \pm 0.26,29.15 \pm 0.43,90.35 \pm 0.81$ and $78.11 \pm 0.63$ respectively. Similarly, the crude fibre (CF) content of Control feed, Experimental feed, Brewery waste, Paddy straw and Brewery waste incorporated paddy straw were carried out as per AOAC (1990) and was $6.34 \pm 0.18,8.88 \pm 0.35,19.62 \pm$ $0.31,34.19 \pm 0.61$ and $30.55 \pm 0.57$ per cent, respectively on dry matter basis.

The in vitro crude fibre disappearance of seven experimental feeds such as control feed, experimental feed with fresh brewery waste (EFFBW), experimental feed with dried brewery waste (EFDBW), fresh brewery waste $(\mathrm{FBW})$, dried brewery waste (DBW), paddy straw (PS) and brewery waste incorporated paddy straw for 3 days (BWIPS) was determined using the rumen simulation technique (RUSITEC) described by Czerkawski and Breckenridge (1977).

The in vitro crude fibre disappearance of experimental feeds were studied at $0,2,6,12$, 24, 48 and 72 hours of incubation in RUSITEC and the experiment was replicated. Each RUSITEC experiment totally consisted of 7 days adaptation period followed by collection period.

Loss in weight of nylon bag after $0,2,6,12$, 24, 48 and 72 hours of incubation in RUSITEC followed by washing and drying was recorded to calculate in vitro crude fibre disappearance.

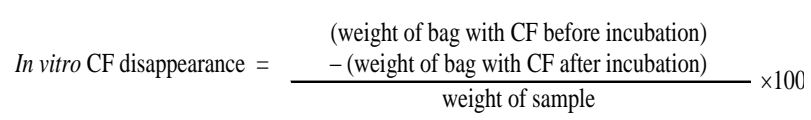

The data were analysed statistically as per the standard statistical methods given by Snedecor and Cochran (1994).

\section{Results and Discussion}

The percentage in vitro disappearance of crude fibre of control feed, experimental feed with fresh brewery waste (EFFBW), experimental feed with dried brewery waste (EFDBW), fresh brewery waste (FBW), dried brewery waste (DBW), paddy straw (PS) and brewery waste incorporated paddy straw (BWIPS) incubated for 0, 2, 6, 12, 24, 48 and 72 hours in RUSITEC are given in Table 2 and is illustrated in Fig. 1.

Table.1 Per cent ingredient composition of the control and experimental concentrate mixtures used

\begin{tabular}{|l|c|c|}
\hline \multirow{2}{*}{ Ingredient } & \multicolumn{2}{|c|}{ Concentrate mixture (\%) } \\
\hline Yellow Maize & Control & Experimental \\
\hline Groundnut Cake & 37.00 & $\mathbf{4 0 . 0 0}$ \\
\hline Wheat bran & 29.00 & $\mathbf{2 1 . 5 0}$ \\
\hline Brewery waste & 30.50 & $\mathbf{1 0 . 0 0}$ \\
\hline Mineral Mixture* & 0.00 & $\mathbf{2 5 . 0 0}$ \\
\hline Salt & 1.00 & $\mathbf{1 . 0 0}$ \\
\hline Shell Grit & 1.00 & $\mathbf{1 . 0 0}$ \\
\hline
\end{tabular}

To every $100 \mathrm{~kg}$ of concentrate mixture 20 grams of Nicomix $\mathrm{AB}_{2} \mathrm{D}_{3} \mathrm{~K}$ (Nicholas Piramal India Ltd, Mumbai) containing Vitamin A82500 I.U, Vitamin $\mathrm{D}_{3}-12000$ I.U, Vitamin $\mathrm{B}_{2}-50 \mathrm{mg}$, Vitamin K-10 mg per gram was added.*Mineral mixture supplied by Kerala Feeds Ltd. Kerala, containing Calcium (minimum) 20 per cent, Phosphorus (minimum) 12 per cent, Magnesium (minimum) 5 per cent, Iron (minimum) 0.4 per cent, Copper (minimum) 0.1 per cent, Zinc (minimum) 0.8 per cent, Manganese (minimum) 0.12 per cent, Cobalt (minimum) 0.012 per cent, Iodine (minimum) 0.026 per cent, Sulphur 1.8 - 3 per cent, Arsenic (maximum) 7 ppm, Lead (maximum) 20 ppm and Flourine (maximum) 0.07 per cent. 
Table.2 In vitro crude fibre disappearance of experimental feeds at different incubation periods (h) in RUSITEC, \%

\begin{tabular}{|l|c|c|c|c|c|c|c|}
\hline \multirow{2}{*}{ Treatments } & \multicolumn{7}{|c|}{ CF Disappearance, \% } \\
\cline { 2 - 8 } & Oh & $2 \mathrm{~h}$ & $6 \mathrm{~h}$ & $12 \mathrm{~h}$ & $24 \mathrm{~h}$ & $48 \mathrm{~h}$ & $72 \mathrm{~h}$ \\
\hline $\begin{array}{l}\text { Control feed } \\
16.30\end{array}$ & 22.00 & 30.83 & 38.86 & 46.72 & 59.81 & 62.54 \\
\hline $\begin{array}{l}\text { Experimental feed with } \\
\text { fresh brewery waste (25\%) }\end{array}$ & 15.61 & 21.45 & 30.38 & 37.38 & 45.70 & 58.47 & 61.67 \\
\hline $\begin{array}{l}\text { Experimental feed with } \\
\text { dried brewery waste (25\%) }\end{array}$ & 15.46 & 20.35 & 27.78 & 35.48 & 44.22 & 55.66 & 60.17 \\
\hline Brewery waste (fresh) & 13.18 & 16.88 & 26.30 & 34.67 & 40.67 & 48.42 & 51.26 \\
\hline Brewery waste (dried) & 11.70 & 15.81 & 24.31 & 32.96 & 40.32 & 42.76 & 44.87 \\
\hline Paddy straw & 10.83 & 15.03 & 22.35 & 24.40 & 27.41 & 30.64 & 33.03 \\
\hline $\begin{array}{l}\text { Brewery waste } \\
\text { incorporated paddy straw }\end{array}$ & 11.36 & 15.83 & 23.18 & 29.24 & 32.36 & 39.27 & 41.76 \\
\hline
\end{tabular}

Fig.1 In vitro crude fibre disappearance of experimental feeds at different incubation periods (h) in RUSITEC, \%

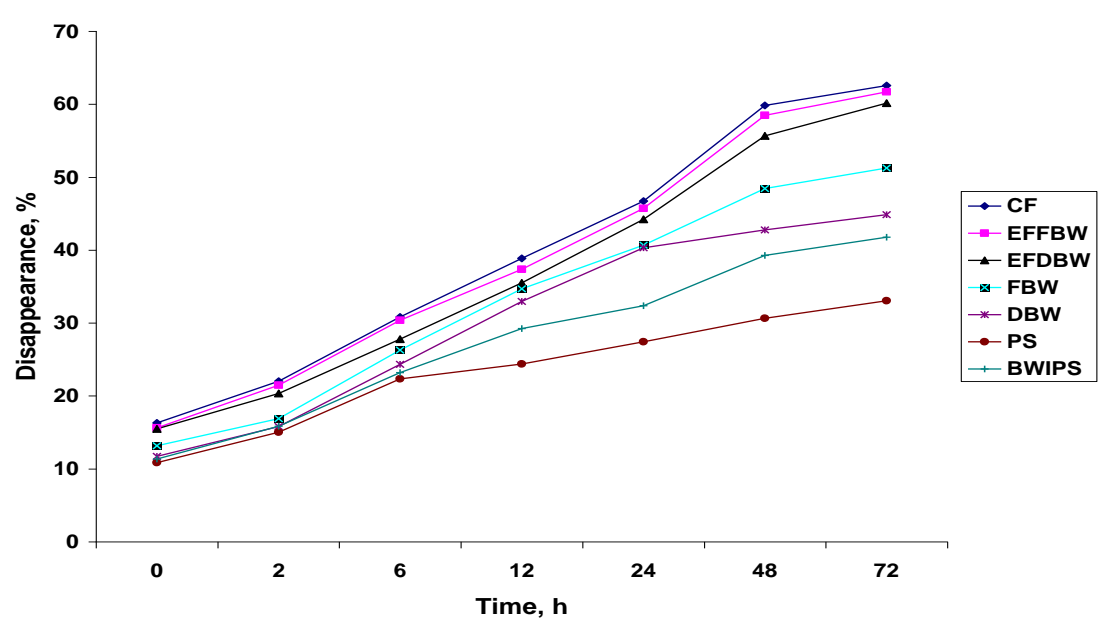

The in vitro crude fibre disappearance of experimental feeds such as control feed, EFFBW, EFDBW, FBW, DBW, PS and BWIPS at 2 hours of incubation in RUSITEC was $22.00,21.45,20.35,16.88,15.81,15.03$ and 15.83 per cent, respectively.

The CF disappearance at 24 hours incubation period was $46.72,45.70,44.22,40.67,40.32$, 27.41 and 32.36 per cent for control feed, EFFBW, EFDBW, FBW, DBW, PS and BWIPS, respectively.
During 72 hours of incubation, 62.54, 61.67, $60.17,51.26,44.87,33.03$ and 41.76 per cent crude fibre disappeared from control feed, EFFBW, EFDBW, FBW, DBW, PS and BWIPS, respectively. Similarly, Carro et al., (1995) found significant improvement in the in vitro (RUSITEC) NDF disappearance of grass and corn silage when nylon bags with pore size of $100 \mu \mathrm{m}$ was used, compared to those with $40 \mu \mathrm{m}$ pore size. Addition of fibrolytic enzymes (30000 nova cellulase and 10000 nova xylanase units per kg DM) 
significantly improved the in vitro (RUSITEC) cellulose and hemicellulose disappearance of orchard grass hay (Dong et al., 1999). Varga and Hoover (1983) also reported that the in situ NDF disappearance of brewer's grain and distiller's grain were 50.8 and 76.6 per cent, respectively, values being higher than that obtained in the present study. They further reported that the in situ rate of degradation of brewer's grain and distiller's grain was 0.071 and 0.072 per hour, respectively. Firkins et al., (1985) reported that the in situ NDF disappearance rates were 4.4 and 3.7 per cent per hour for wet and dry corn distiller's grain, respectively in rumen cannulated steers. Al-suwaeigh et al., (2002) reported in situ NDF disappearance of wet sorghum distiller's grain as 45.2 per cent, which is comparable to the findings of the present study while that of wet corn distiller's grain as 39 per cent which is lower than the present values obtained for fresh and dried brewery waste.

Among the feeds experimented in RUSITEC, disappearance was more in the control feed, EFFBW and EFDBW when compared to other experimental feeds. Similarly, the disappearance was more in BWIPS compared to paddy straw. The in vitro crude fibre disappearance at all incubation periods was higher for FBW than the DBW. The FBW had more disappearance compared to DBW. A low in vitro crude fibre disappearance of 33.03 per cent was recorded at 72 hours of incubation for paddy straw, whereas the BWIPS had improved in vitro crude fibre disappearance of 41.76 per cent at 72 hours of incubation.

\section{Acknowledgement}

The Author is thankful to the Dean, College of Veterinary and Animal Sciences, Mannuthy, Kerala Agricultural University, Thrissur, Kerala, India for the facilities and financial support provided to carry out this research.

\section{References}

Al-Suwaiegh, S., K.C. Fanning, R.J. Grant, C.T. Milton, and T.J. Klopfenstein. 2002. Utilization of distiller's grains from the fermentation of sorghum or corn in diets for finishing beef and lactating dairy cattle. J. Anim Sci., 80: 1105-1111.

AOAC. 1990. Official Methods of Analysis, Fifteenth edition. Association of Official Analytical Chemists. Washington D.C., p. 587.

Carro, M.D., P. Lebzien, and K. Rohr. 1995. Effects of pore size of nylon bags and dilution rate on fermentation parameters in a semi-continuous artificial rumen. Small Ruminant Res., 15: 113-119.

Czerkawski, J.W. and G. Breckenridge. 1977. Design and development of a long term rumen simulation technique (RUSITEC). Br. J. Nutr., 38: 371-384.

Dong, Y., H.D. Bae, T.A. McAllister, G.W. Mathison, and K.J. Cheng. 1999. Effects of exogenous fibrolytic enzymes, $\alpha$-bromoethanesulfonate and monensin on digestibility of grass hay and methane production in a rumen simulation (Rusitec) system. Can. J. Anim. Sci., 79: 491-498.

Firkins, J.L., L.L. Berger, and G.C.Jr. Fahey. 1985. Evaluation of wet and dry distiller's grains and wet and dry corn gluten feeds for ruminants. J. Anim. Sci., 60: 847.

Rasco, B.A., M. Borhan, and Y. OwusuAnsah. 1989. Effects of drying techniques and incorporation of soluble solids on the chemical composition and color of distiller's grain products. Cereal Foods Wld., 34: 346-349. 
Snedecor, G.W. and W.G. Cochran. 1994. Statistical Methods. Eighth edition. The Iowa state University press, Ames, Iowa, p. 313. and extent of neutral detergent fibre degradation of feedstuffs in situ. $J$. Dairy Sci., 66: 2109-2115.

Varga, G.A. and W.H. Hoover. 1983. Rate

\section{How to cite this article:}

Senthilkumar, S. 2020. In vitro Crude Fibre Disappearance of Brewery Waste Incorporated Paddy Straw in Rusitec. Int.J.Curr.Microbiol.App.Sci. 9(08): 2215-2219. doi: https://doi.org/10.20546/ijcmas.2020.908.253 